\title{
The distribution of basal motion beneath a High Arctic polythermal glacier
}

\author{
Luke GOPLAND, ${ }^{1}$ Martin J. SHARP, ${ }^{1}$ Peter NienOW, ${ }^{2}$ Robert G. BINGHAM ${ }^{2}$ \\ ${ }^{1}$ Department of Earth and Atmospheric Sciences, University of Alberta, Edmonton, Alberta T6G 2E3, Canada \\ E-mail: martin.sharp@ualberta.ca \\ ${ }^{2}$ Department of Geography and Topographic Science, University of Glasgow, Glasgow G12 8QQ, Scotland
}

\begin{abstract}
The longitudinal pattern of surface velocity of a large, predominantly cold, polythermal glacier (John Evans Glacier, Ellesmere Island, Canada) was measured over summer and winter periods. In the accumulation and upper ablation areas, where ice is predominantly cold-based, summer velocities were slightly higher than overwinter velocities. Predicted velocities due to ice deformation alone in these areas closely matched these observations in the winter, with limited basal motion likely in the summer. In the lower ablation area, where ice is likely warm-based, measured summer velocities were up to double overwinter velocities. Predicted ice deformation could not account for all of these measured velocities in either summer or winter. This suggests that basal motion occurs throughout the year over at least part of the lower ablation area. This finding is supported by radio-echo sounding, subglacial drainage reconstructions and analyses of early-summer meltwater chemistry, which suggest that subglacial water is present throughout the year in this region. In summer, basal motion may account for up to $75 \%$ of the total surface velocity throughout the lower ablation area. The inferred rate of basal motion increases sharply directly below a set of moulins by which most surface meltwater reaches the glacier bed.
\end{abstract}

\section{INTRODUGTION}

Subglacial water is an important influence on the basal motion of temperate glaciers, where short-term highvelocity events often correspond to episodes of large transient subglacial water pressures (Iken and Bindschadler, 1986; Paterson, 1994; Willis, 1995). By contrast, the influence of subglacial water on the motion of predominantly cold polythermal glaciers, in which ice only reaches the pressuremelting point at and immediately above restricted areas of the glacier bed, is not well known. A common view is that surface meltwaters have difficulty penetrating to the beds of such glaciers, and that variations in surface melt rates therefore have little impact on glacier motion (Hodgkins, 1997). This is because, in cold ice, water flow along intergranular vein networks is limited, and large-scale permeability associated with crevasses and moulins is poorly developed due to low rates of ice deformation.

A number of studies, however, suggest that substantial basal motion occurs over parts of the ablation zones of predominantly cold polythermal glaciers, at least in the summer. For example, Andreasen (1985) observed seasonal velocity fluctuations at Kitdlerssuaq Glacier, West Greenland, and Zwally and others (2002) observed similar variations on the Greenland ice sheet at a location where cold ice was $>1200 \mathrm{~m}$ thick. Iken (1974) found a strong relationship between short-term summer velocity increases and water pressures in nearby moulins at White Glacier, Axel Heiberg Island, Canada. At McCall Glacier, Alaska, U.S.A., Rabus and Echelmeyer (1997) observed summer velocity increases of up to $75 \%$ above mean winter values, and concluded that basal motion occurred year-round beneath a $2 \mathrm{~km}$ long section of the lower glacier, where it accounted for $>70 \%$ of the total motion.

Transmission of surface meltwaters to the beds of predominantly cold glaciers provides a mechanism by which the flow of such glaciers may respond rapidly to changes in surface weather and climate (Zwally and others, 2002). It is therefore important to establish the range of environmental conditions under which this process can occur. This paper reports the results of measurements made on John Evans Glacier, Ellesmere Island, Canada. Climatic conditions at John Evans Glacier are cold and dry (mean annual air temperature approximately $-15^{\circ} \mathrm{C}$, mean annual precipitation $<0.15 \mathrm{~m} \mathrm{a}^{-1}$ ), and the summer melt season typically lasts for only $\sim 60$ days. Outflow of subglacial waters ceases completely in winter, and is restricted to a period of 2-6 weeks in summer (Skidmore and Sharp, 1999). The goals of this paper are to determine: (a) whether basal motion occurs beneath this predominantly cold polythermal glacier, (b) whether basal motion occurs year-round or is restricted to the summer melt season, and (c) how the spatial distribution of basal motion compares with basal thermal and hydrological conditions inferred from field observations and radio-echo sounding (Copland and Sharp, 2001).

The analysis presented here is based on measurements of summer and winter surface velocities at 20 locations along the length of John Evans Glacier. These measurements are compared with ice deformation velocities predicted from measured ice thicknesses and surface slopes, taking into account the effects of longitudinal stress gradients. Basal motion is assumed to occur where observed surface velocities consistently exceed predicted deformation velocities. The term basal motion is used to refer to any motion at the base of the glacier 


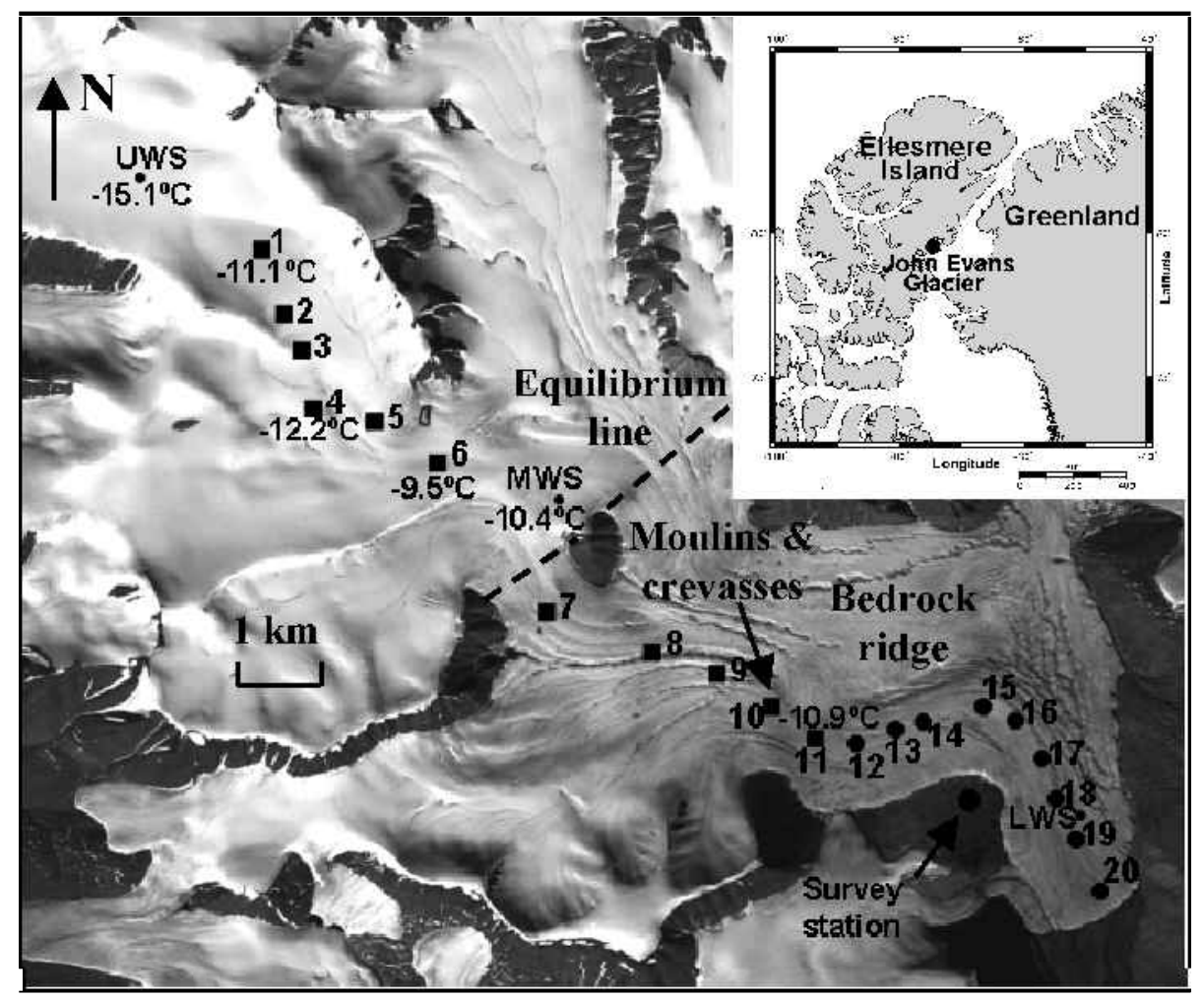

Fig. 1. Location of John Evans Glacier (inset), and the longitudinal velocity stake network superimposed on a Landsat 7 image (path 049, row 002, 10 July 1999). Squares indicate stakes measured by GPS, while circles indicate stakes measured by theodolite. LWS, MWS and UWS mark the lower, middle and upper weather stations, respectively. Temperatures mark ice temperatures at $15 \mathrm{~m}$ depth.

that is not due to ice deformation. It therefore encompasses motion by basal sliding and/or basal sediment deformation.

To place limits on the possible range of rates of basal motion, ice deformation rates were calculated for different longitudinal coupling lengths (Kamb and Echelmeyer, 1986). Longitudinal coupling occurs due to longitudinal stress gradients that arise from along-glacier variations in ice thickness and surface slope. It modifies the flow at each point on the glacier from that which would occur if local flow were determined directly by the local slope and ice thickness (i.e. according to the basic flow theory that applies in the absence of longitudinal gradients (Nye, 1952, 1957)). The longitudinal coupling leng th provides the fundamental length scale in the longitudinal averaging of the effects of perturbations in ice thickness and surface slope on the local flow. It is highly dependent on ice rheology, and the coupling length typically increases as ice temperature decreases (Kamb and Echelmeyer, 1986).

\section{JOHN EVANS GLACIER}

John Evans Glacier is located on the central east coast of Ellesmere Island, Nunavut, Canada $\left(79^{\circ} 40^{\prime} \mathrm{N}, 74^{\circ} 30^{\prime} \mathrm{W}\right.$; Fig. 1). It is approximately $20 \mathrm{~km}$ long, ranges in elevation from 100 to $1500 \mathrm{~m}$ a.s.l., and covers an area of approximately $165 \mathrm{~km}^{2}$. Radio-echo sounding indicates a mean ice thickness of $\sim 150 \mathrm{~m}$ in the terminus area, and a maximum ice thickness of almost $400 \mathrm{~m}$ close to the equilibrium line at 750-850 m a.s.l. (Copland and Sharp, 2000).

The melt season typically extends from early June to early August each year. During this time, most surface runoff from the lower ablation area (stakes 10-20) flows off the glacier margins. Most surface runoff from the accumulation and upper ablation areas (stakes 1-9) sinks to the glacier bed via a series of moulins located in a crevasse field between stakes 9 and 10 (Fig. 1). Dye tracing shows that the sediment-free and low-electrical-conductivity (low-EG) water $\left(<10 \mu \mathrm{S} \mathrm{cm}^{-1}\right)$ that enters the moulins in summer is released at the glacier terminus as sediment-laden and high-EC water $\left(>100 \mu \mathrm{S} \mathrm{cm}^{-1}\right)$ within a period of hours to days (Bingham and others, 2003). Thus, this water likely flows along the glacier bed. Subglacial outflow ceases in winter, when the glacier freezes to its bed around the margins. Meltwater is apparently trapped behind the snout by the thermal dam that results, and is released when outflow resumes following the penetration of surface waters to the glacier bed the following melt season (typically in late June to early July). The first meltwaters to be released from the glacier bed each summer have an EC of $>350 \mu \mathrm{S} \mathrm{cm}^{-1}$ (Skidmore and Sharp, 1999). In the late summer, moulins may also open just down-glacier of stake 6 in the lower accumulation area and drain meltwater from the upper glacier.

\section{MEASUREMENTS}

\subsection{Ice temperature}

In the period 1997-99, the mean annual air temperature measured at three automatic weather stations located at the terminus, equilibrium-line altitude (ELA) and summit of the glacier was $-14.8^{\circ} \mathrm{C}$ (Fig. 1). Near-surface ice temperatures were determined by drilling $15 \mathrm{~m}$ deep boreholes, placing a thermistor in the base of each and then refilling the borehole with snow and ice. After allowing several weeks for the temperatures to stabilize, the temperatures at $15 \mathrm{~m}$ depth in the accumulation and upper ablation areas ranged 


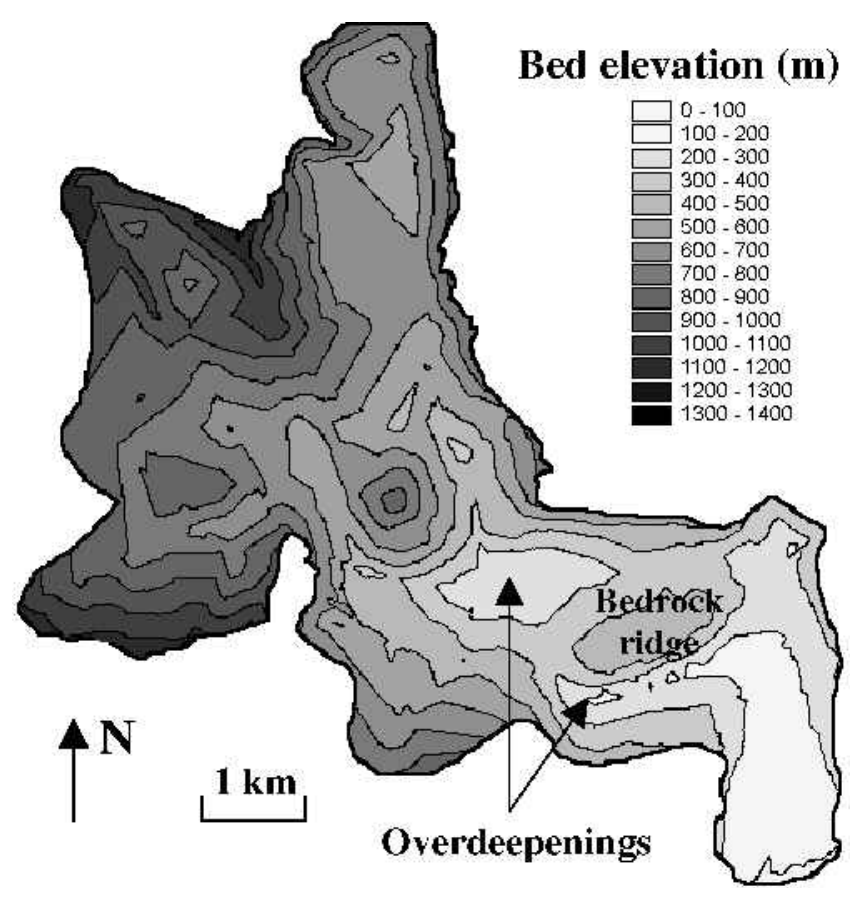

Fig. 2. Bedrock topography at fohn Evans Glacier determined from radio-echo sounding (Copland and Sharp, 2001).

between $-9.5^{\circ}$ and $-15.1^{\circ} \mathrm{C}$ (Fig. 1). Radio-echo sounding measurements of residual bed reflection power suggest that ice in the accumulation area is cold throughout, while ice reaches the pressure-melting point at the bed over much of the ablation area. A layer of warm basal ice $\sim 25 \mathrm{~m}$ thick may exist in the centre of the terminus region, and warm basal conditions appear to exist in the overdeepenings in the ablation area (Fig. 2). However, the glacier is likely frozen to its bed around its margins and over a large bedrock ridge in the centre of the ablation area (Copland and Sharp, 2001).

\subsection{Surface velocity}

Twenty velocity stakes were drilled and frozen into the ice surface along the length of the glacier (Fig. 1). Due to the complex flow structure of John Evans Glacier, and the difficulty of working in some areas due to crevassing and large supraglacial streams, it was impossible to establish a stake line that exactly followed a single flowline from the summit of the glacier to the terminus. The stakes are, however, everywhere aligned approximately in a downslope direction, and convergence/divergence of the flowlines is not appreciable on the length scale of the longitudinal filtering discussed later. Stakes 1-6 and 9-20 follow single flowlines quite closely, but stakes 7 and 8 are staggered between the other two groups of stakes, and the stake array cuts across flowlines in this area (Fig. 1).

The stakes were surveyed regularly to determine surface velocities over both summer and winter periods. The lower 9 stakes were surveyed with a Geodimeter 540 total station theodolite from a station located on bedrock. The upper 11 stakes were out of range of the theodolite, so were surveyed with a differential global positioning system (GPS). To ensure consistency between measurements, reported summer velocities relate to the last 2-3 weeks of July, while overwinter velocities represent the period between the last survey of one year and the first survey of the next (typically early August to late May). Most overwinter velocities were measured in 1999/

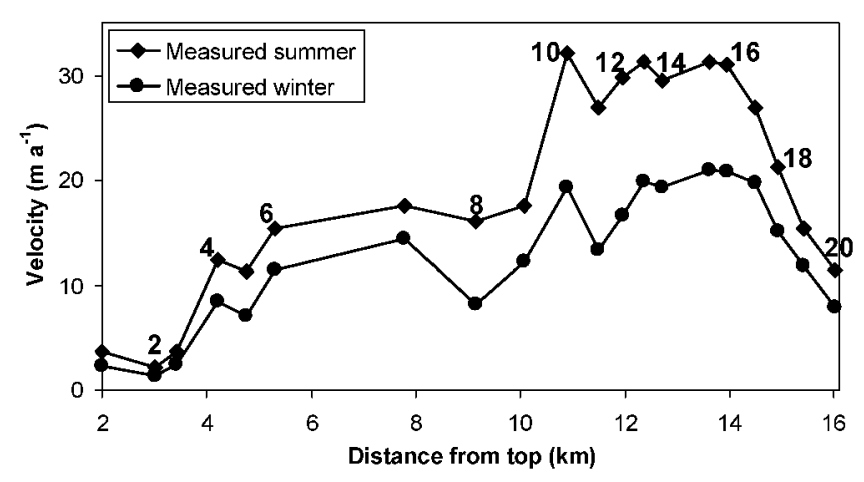

Fig. 3. Measured summer and winter velocities along the velocity stake network ( see Fig. 1 for stake locations).

2000, and most summer velocities in 1999. Exceptions (due to poor or missing data) are that summer 2000 velocities were used for stakes 1-3, while the overwinter 1998/99 velocity was used for stake 15 . Where surface velocities were recorded at the same stake in different years, they differed by $<10 \%$. To enable comparison of summer and winter measurements, all velocities are expressed in $\mathrm{m} \mathrm{a}^{-1}$.

Errors in the theodolite measurements were determined by surveying each stake at least twice per daily survey in July 1999 (the original dataset was subsampled to produce the velocities reported here). The difference between the two or more measurements of a stake and its mean location for a given survey provide a mean position error of $\pm 0.6 \mathrm{~cm}$. Assuming that successive position errors are of opposite sign, the maximum horizontal displacement error averages $\pm 1.2 \mathrm{~cm}$. This produces a mean velocity error of $\pm 0.2 \mathrm{~m} \mathrm{a}^{-1}$ over a typical 20 day summer measurement period, and \pm 0.02 $\mathrm{m} \mathrm{a}^{-1}$ over a typical 300 day overwinter measurement period.

An estimate of the errors in the differential GPS measurements is provided directly by the instrument, and averages $\pm 1.0 \mathrm{~cm}$ for the positioning of a stake. This equates to a maximum displacement error of $\pm 2.1 \mathrm{~cm}$ if successive position errors are assumed to be of opposite sign. This equates to a maximum mean velocity error of $\pm 0.4 \mathrm{~m} \mathrm{a}^{-1}$ over a 20 day summer measurement period, and $\pm 0.03 \mathrm{ma}^{-1}$ over a 300 day overwinter measurement period. These errors are much lower than the measured velocities (Fig. 3) and give confidence that measurements over these time-scales provide an accurate picture of the surface velocity field. It is also likely that some errors arise from factors such as the tilting of stakes by wind or melt between surveys, but these influences are likely small in comparison to the true velocity.

\subsection{Glacier geometry}

A digital elevation model (DEM) of the glacier surface was derived from 1959 stereo aerial photography (Woodward and others, 1997) and verified against the 1999 differential GPS measurements. On average, the surface elevation at the stakes was $7.3 \mathrm{~m}$ lower in 1999 than in 1959, although the elevation change did not vary in a consistent way with distance along the glacier, and the surface at some stakes was at a higher elevation in 1999 than in 1959. Comparison of the original aerial photography with 1999 Landsat 7 imagery shows that John Evans Glacier has changed little over the last 40 years, and suggests that the surface DEM is representative of present surface conditions. The surface DEM was interpolated to a regular grid with $25 \mathrm{~m}$ spacing, and was used in 
the calculation of the surface slopes used as input for the ice deformation calculations discussed later. The mean surface slope at a point was determined from the change in elevation between gridpoints $100 \mathrm{~m}$ to the north, east, south and west of that point (Zevenbergen and Thorne, 1987).

Ice thicknesses at 3200 locations were determined from ground-based radio-echo sounding conducted between 1997 and 1999 (Copland and Sharp, 2000, 2001). A DEM of the glacier bed was produced by subtracting the ice thickness from the surface DEM elevation at each measurement location, and interpolating the resulting bed elevations to a $25 \mathrm{~m}$ grid that matched the surface DEM (Fig. 2). Errors in the bed DEM arise from errors in both the surface DEM and the ice-thickness calculations, and are estimated at 1020\% of the local ice thickness (Copland and Sharp, 2001). Errors of this magnitude make little difference to the ice deformation calculations discussed later.

\section{RESULTS}

\subsection{Measured surface velocities}

Along the stake network, velocities are relatively low $\left(<18 \mathrm{~m} \mathrm{a}^{-1}\right)$ in the accumulation and upper ablation areas (stakes 1-9), with a slight increase in the summer compared to the winter (Fig. 3). Further down-glacier, there is a large velocity increase between stakes 9 and 10. This is particularly true in the summer, when the velocity increases from $17.5 \mathrm{~m} \mathrm{a}^{-1}$ at stake 9 to $32.1 \mathrm{~m} \mathrm{a}^{-1}$ at stake 10 over a horizontal distance of $800 \mathrm{~m}$. This occurs in an area that contains numerous moulins and transverse crevasses by which supraglacial meltwater can reach the glacier bed (Fig. 1). Between stakes 10 and 17, surface velocities reach their peak in both winter and summer. Summer velocities are on average $62 \%$ higher than winter velocities in this region. Locally, they may be up to double overwinter levels (e.g. stake 11). Towards the glacier terminus, velocity decreases downglacier of stake 18, although velocities are still higher in the summer than in the winter.

\subsection{Predicted ice motion}

\subsubsection{Predicted ice motion without longitudinal stresses}

If longitudinal stresses are ignored, the surface velocity due to ice deformation $\left(u_{\mathrm{d}}\right)$ at any point along the centre line of a glacier flowing in a channel of parabolic cross-section can be described by (Nye, 1965; Rabus and Echelmeyer, 1997):

$$
u_{\mathrm{d}}=\frac{2 A}{n+1}(\rho g f \sin \alpha)^{n} h^{n+1}
$$

where $A$ is the flow-law parameter, $n$ is the flow-law exponent (3), $\rho$ is the density of ice, $g$ is the acceleration due to gravity, $f$ is the shape factor and $h$ is ice thickness. To evaluate Equation (1), a longitudinal transect with $100 \mathrm{~m}$ grid spacing was defined that passes through the DEM gridcells in which the stakes are located. The bed and surface topography, together with the values of $f, h$ and $\alpha$ at each velocity stake, are shown in Figure 4. The value of $f$ is based on the half-width/depth ratio along the velocity stake network (Paterson, 1994), and is generally close to 1 due to the relatively large channel width. In all figures, values are shown only for gridcells that contain velocity stakes, as these are the only locations for which velocity measurements and predictions can be compared.

The value of $A$ depends mainly on ice temperature (Pat-
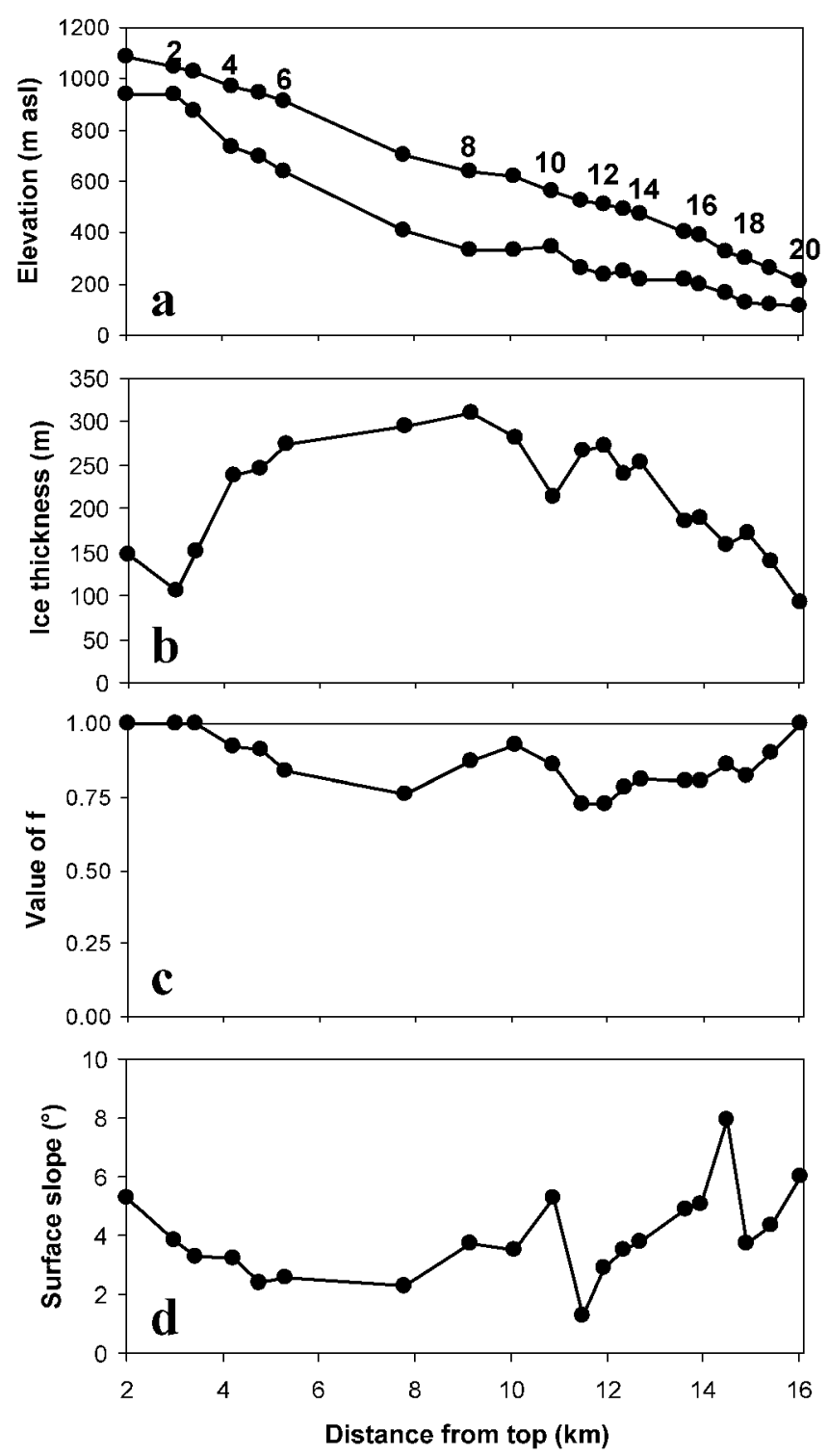

Fig. 4. For the velocity stake network: (a) surface and bed topography; (b) ice thickness; (c) shape factor; (d) surface slope angle.

erson, 1994). This suggests that variations in ice temperature may cause large spatial variations in ice motion when the ice is non-temperate. Based on the information presented in section 3.1, two scenarios were created to represent the likely upper and lower limits of ice temperatures at John Evans Glacier:

(a) Warm: depth-weighted mean ice temperatures of $-5^{\circ} \mathrm{C}$ in the accumulation and upper ablation areas (stakes 1-9) and $-2{ }^{\circ} \mathrm{C}$ in the lower ablation area (stakes $10-20$ ).

(b) Cold: depth-weighted mean ice temperatures of $-10^{\circ} \mathrm{C}$ in the accumulation and upper ablation areas (stakes 1-9), and $-5^{\circ} \mathrm{C}$ in the lower ablation area (stakes 10-20).

Although these scenarios are crude estimates of the true ice-temperature distribution, they are expected to bracket the range of likely conditions and thus provide upper and lower limits to the ice deformation calculations. The values of $A$ that relate to these temperature distributions are $2.4 \times 10^{-24} \mathrm{~Pa}^{-3} \mathrm{~s}^{-1}$ at $-2^{\circ} \mathrm{C}, 1.6 \times 10^{-24} \mathrm{~Pa}^{-3} \mathrm{~s}^{-1}$ at $-5^{\circ} \mathrm{C}$, and $4.9 \times 10^{-25} \mathrm{~Pa}^{-3} \mathrm{~s}^{-1}$ at $-10^{\circ} \mathrm{C}$ (Paterson, 1994, p. 97).

The surface velocities predicted by Equation (1) for the two temperature scenarios are shown in Figure 5, together with the 


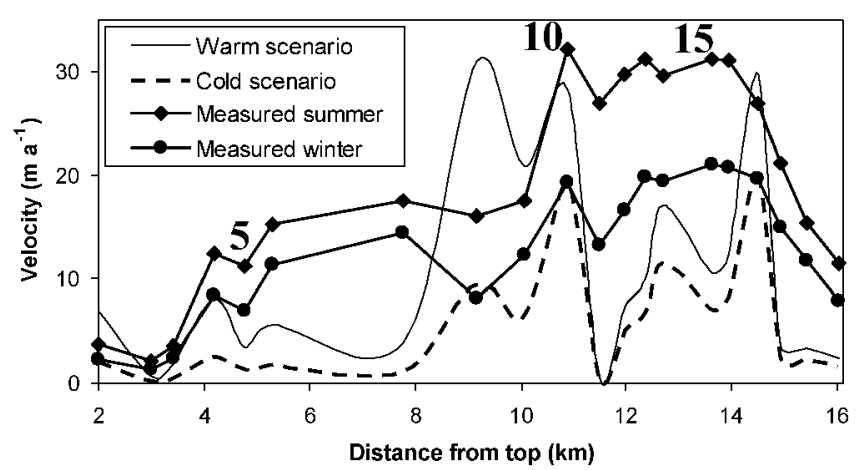

Fig. 5. Comparison between measured and predicted surface velocities along the velocity stake network from Equation (1), without accounting for longitudinal stresses.

measured velocities. The fit between the predicted and measured velocity is generally poor, with under-prediction at virtually all stakes using the cold scenario, particularly in the accumulation area. The fit with the warm scenario is better in the upper accumulation area (stakes 1-4), but fluctuates between large over- and under-prediction in the ablation area (stakes 7-20). The high frequency variability in predicted velocities is attributable to large local variations in surface slope and ice thickness, which are not smoothed out due to the failure of Equation (1) to take longitudinal coupling into account. Clearly, longitudinal stresses need to be included to improve the predictions of surface velocity.

\subsubsection{Predicted ice motion with longitudinal stresses}

To take longitudinal stresses into account in the determination of surface velocity $\left(u_{\mathrm{s}}\right)$, the approach of Kamb and Echelmeyer (1986) and Rabus and Echelmeyer (1997) was adopted. In this method, surface velocities are not predicted directly from physical parameters as in Equation (1). Instead, they are predicted from the differences between local ice conditions and those at a datum location $\left(x_{0}\right)$ on the glacier where the surface velocity has been measured $\left(u_{\mathrm{obs}}\right)$ :

$$
u_{\mathrm{s}}(x)=u_{\mathrm{obs}}\left(x_{0}\right) \exp \left(B(x)-B\left(x_{0}\right)\right),
$$

where $x$ is the location where $u_{\mathrm{s}}$ is evaluated, and $B$ is determined from averaging the effect of $\alpha, f$ and $h$ with a triangular weighting function of unit value:

$$
B(x)=\int_{x-2 l}^{x+2 l}[n \ln (\alpha f)+(n+1) \ln h]\left(1-\frac{\left|x^{\prime}-x\right|}{2 l}\right) \mathrm{d} x^{\prime},
$$

where $l$ is the longitudinal coupling length, and $x^{\prime}$ is the distance between $x$ and the location at which the integral is being evaluated. For John Evans Glacier, the integral was evaluated as a sum at a spacing $\Delta x^{\prime}$ of $100 \mathrm{~m}$ over a total distance of $\pm 2 l$ from $x$. The triangular weighting function gives most importance to the values of $\alpha, f$ and $h$ at location $x$, and progressively less importance to these values at sites more distant from $x$. This approach does not account for possible variations in ice temperature along the glacier, but rather assumes that the ice temperature at the datum location is representative of the glacier as a whole. For points beyond the glacier boundary, the ice thickness and surface slope are set to 0 .

An important consideration in the evaluation of Equation (2) is the choice of which stake to use as the datum location. Since the aim is to predict velocities due to ice deformation, it makes most sense to choose a datum stake

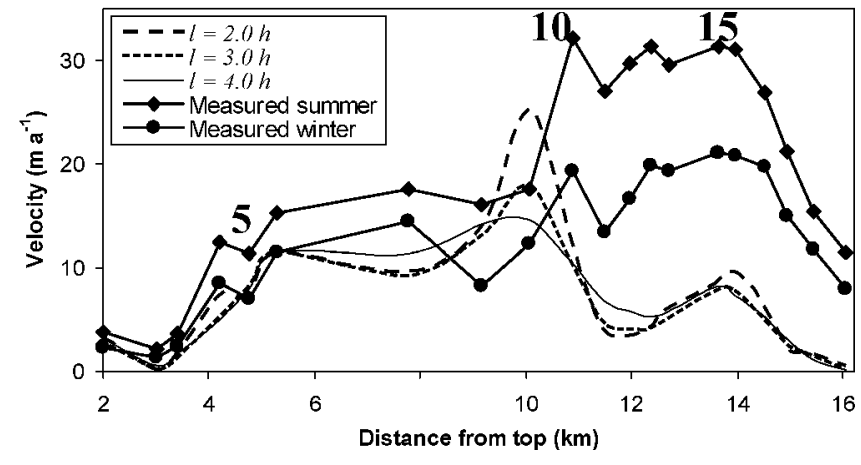

Fig. 6. Comparison between measured and predicted surface velocities along the velocity stake network from Equations (2) and (3) for longitudinal coupling lengths of 2, 3 and 4 times the local ice thickness. The measured winter velocity at stake 6 is used as the datum. Ice temperature variations are not taken into account.

in the accumulation area. The small difference in surface velocity between summer and winter in this region suggests that basal motion is not as important here as it is in the ablation area (Fig. 3). Indeed, simulations that use stakes in the ablation area as the datum (stakes 10-20) dramatically over-predict (by two times or more) velocities in the accumulation area. In contrast, when stakes in the accumulation area (stakes 1-6) are used as the datum, there is generally a good fit between observed and predicted velocities in the upper glacier and an under-prediction in the lower glacier.

To determine which stake was the most suitable choice as the datum location, a series of calculations was performed using the measured winter velocity at each stake in the accumulation area in turn as the datum. The best results were obtained using stake 6 , which produces a generally good fit between measured and predicted winter velocities for stakes $1-9$ in the accumulation and upper ablation areas, and an under-prediction of velocities for stakes 10-20 in the lower ablation area (Fig. 6). The values of $\alpha, f$ and $h$ are all close to the longitudinal average at stake 6 (Fig. 4).

The velocities predicted using longitudinal coupling lengths of 2, 3 and 4 times the local ice thickness (with the winter velocity at stake 6 as the datum) are shown in Figure 6. It is clear that the inclusion of longitudinal coupling damps the unrealistic high-amplitude velocity variations that were produced by Equation (1) (as shown in Fig. 5), and that the best fit to upper glacier velocities is provided by $l=4 h$. With longitudinal coupling lengths $>4 h$, local variability tends to be lost and there is no further significant reduction in the magnitude of the residuals. Kamb and Echelmeyer (1986) state that $l / h$ is typically in the range $1-3$ for temperate valley glaciers and 4-10 for ice sheets. The value of 4 therefore seems reasonable for a large polythermal ice mass such as John Evans Glacier.

\section{DISGUSSION}

\subsection{Winter basal motion}

The ice deformation velocities predicted by Equation (2) are well below the measured summer and winter surface velocities across the lower ablation area of John Evans Glacier (Fig. 6). As discussed above, the large difference between summer and winter surface velocities suggests that 


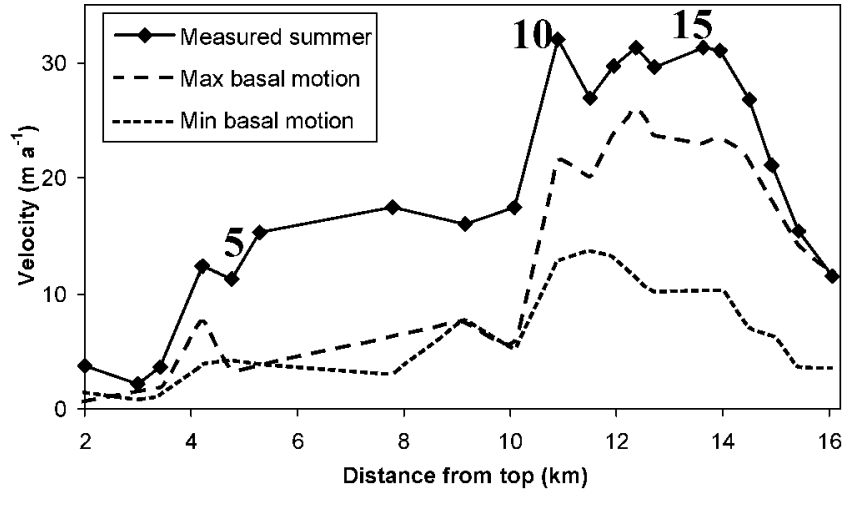

Fig. 7. Likely range of basal motion at John Evans Glacier in the summer. Minimum basal motion is calculated from the difference between the measured summer and winter surface velocities. Maximum basal motion is calculated from the difference between the measured summer surface velocity and the predicted deformation rate from Equation (2) (except at stakes 8 and 9 , where it is set to the same as the minimum basal motion due to the over-prediction of deformation rates at these stakes (see Fig. 6)).

basal motion occurs in the summer, at least between stakes 10 and 20. The question remains, however, as to whether basal motion also occurs in this region during the winter. The fact that the predicted velocities in this region are well below the measured winter velocities suggests that basal motion does occur in winter. However, the failure of Equation (2) to take into account spatial variations in ice temperature may also provide an explanation since ice temperatures can and do vary substantially along the leng th of predominantly cold polythermal glaciers (Blatter, 1987; Blatter and Kappenberger, 1988).

The lack of deep borehole temperature measurements makes it difficult to determine the importance of variations in ice temperature at John Evans Glacier. As a first approximation, however, the warm and cold temperature scenarios outlined in section 4.2.1 (i.e. differences of $3-5^{\circ} \mathrm{C}$ between the ablation and accumulation areas) can be used to assess their potential significance. Since the effect of the value of $A$ on ice deformation in Equation (1) is linear, it is possible to estimate the flow enhancement produced by these assumed temperature differences. The detailed results are not presented here due to their approximate nature, but they indicate that it is not possible to account for all of the measured surface winter velocity between stakes 10 and 20 by deformation alone unless the velocity at stakes 15 and 16 is substantially over-predicted.

Thus, it seems likely that basal motion is significant over at least part of the lower ablation area (stakes 10-20) in the winter. This is consistent with our current knowledge of the basal hydrological system of the glacier. As discussed by Copland and Sharp (2001), the area beneath stakes 11-14 is overdeepened by up to $50 \mathrm{~m}$ in comparison to surrounding basal topography (Fig. 2). High residual bed reflection powers from radio-echo sounding measurements made in May suggest that basal water is present in this area prior to the initiation of surface melt. This may imply that basal water is stored over winter in the overdeepening.

In addition, there is evidence that water is present at the glacier bed throughout the year beneath stakes 18-20. The thermal dam at the glacier margin likely traps basal water behind it once the subglacial outlet is closed by ice deformation and freezing after surface runoff ceases at the end of the summer. The occurrence of trapped basal water is supported by the progressive increase in residual bed reflection power towards the glacier terminus in radio-echo sounding records (Copland and Sharp, 2001). As at stakes 11-14, most of these measurements were made before the onset of surface melting, implying that basal water is present throughout the winter beneath this part of the glacier. Further evidence for the overwinter storage of subglacial water is provided by water chemistry (Skidmore and Sharp, 1999; Heppenstall, 2002). The first water to be released from the glacier after the thermal dam at the snout breaks in the summer has a very high EC ( $\left.>350 \mu \mathrm{S} \mathrm{cm}^{-1}\right)$, and contains ionic species such as lithium that are indicative of long water/rock contact times and that are not present at detectable levels later in the melt season. In contrast, water that is released later in the summer is more dilute $\left(\mathrm{EC}<200 \mu \mathrm{S} \mathrm{cm}^{-1}\right)$, and contains more suspended sediment, indicative of more rapid subglacial water flow and lower water/rock contact times. All of these independent sources of evidence support the contention that subglacial water is stored over winter behind the glacier snout, and that basal motion could occur there during the winter.

\subsection{Summer basal motion}

The likely range of basal motion during the summer can be defined by:

1. Minimum: the measured winter surface velocity is assumed to be entirely due to ice deformation (which is unlikely given the discussion above). The minimum basal motion is then defined by the difference between the measured summer and winter surface velocities. This assumes that there are no significant seasonal variations in ice deformation.

2. Maximum: Equation (2) is assumed to describe accurately the velocity due to ice deformation. The maximum basal motion is defined by the difference between the measured summer surface velocity and the predicted ice deformation shown in Figure 6 (for a longitudinal coupling length of $4 h$, with winter velocity at stake 6 as the datum). This ignores possible flow enhancement caused by warmer ice temperatures in the lower ablation area, which would have the effect of increasing deformation rates and reducing inferred basal motion.

Figure 7 shows the range of basal motion predicted by these scenarios, and indicates the substantial contribution that basal motion provides to total surface velocity in the lower ablation area (stakes 10-20) in the summer. On average, basal motion accounts for a minimum of $35 \%$ and a maximum of $81 \%$ of total summer surface velocity in this region. Locally, maximum basal motion accounts for up to $98 \%$ of the total summer surface velocity in areas close to the snout.

The rapid onset of basal motion between stakes 9 and 10 in the summer is consistent with the observed delivery of large volumes of surface water to the glacier bed via the crevasses and moulins in this area (Fig. 1). Radio-echo sounding and meltwater chemistry indicate that the glacier bed is warm and wet below these moulins. Dye tracing shows that subglacial water passes from the moulins to the snout (a distance of $\sim 4 \mathrm{~km}$ ) in a matter of hours in the late summer (Bingham and others, 2003). The thermal dam at the snout 
also appears to play a role in producing very high basal water pressures beneath the lower terminus in the early summer. Evidence for basal water pressures of at least $120 \%$ of ice overburden pressure is provided by the occurrence of an artesian fountain $\sim 200 \mathrm{~m}$ up-glacier from the snout in early July 1998 (Copland and others, 2003).

Figure 7 also suggests that basal motion may occur over the upper ablation area (stakes 7-9) and lower accumulation area (stakes 4-6) in the summer. A longitudinal coupling length of $4 h$ suggests that the summer velocity increases in the upper ablation area may be attributable to the hydrological forcing provided by the moulins between stakes 9 and 10 . However, this does not account for the higher summer velocities observed in the lower accumulation area. A more likely explanation relates to the moulins that have been observed to open just down-glacier of stake 6 towards the end of the melt season (mid-July). Although water flow into these moulins is short-lived ( $\sim 2$ weeks), discharges into them can be significant $\left(\sim 5 \mathrm{~m}^{3} \mathrm{~s}^{-1}\right)$. Dye tracing indicates that they are connected to the glacier terminus via a partially distributed drainage system (Bingham and others, 2003). These observations suggest that water input into these upper moulins reaches the glacier bed and results in basal motion in the late summer in the lower accumulation and upper ablation areas.

As discussed in section 3.1, low residual bed reflection powers in radio-echo sounding suggest that the glacier ice is cold throughout the accumulation area (Copland and Sharp, 2001). These measurements were made in May, before the start of the melt season, so do not preclude the possibility that localized regions of the bed in the accumulation area reach the melting point in late summer. Presumably, the transient water inputs provided by the opening of the upper moulins produce short-lived subglacial drainage pathways which freeze shut over winter and would not be detected in radioecho sounding measurements in the spring.

\section{GONGLUSIONS}

Interpretation of seasonally resolved surface velocity measurements along the length of John Evans Glacier suggests that basal motion occurs throughout the year beneath the lower ablation area of this predominantly cold polythermal glacier. The inferred distribution of basal motion is broadly consistent with mapping of residual bed reflection power by radio-echo sounding (Copland and Sharp, 2001). This suggests that ice is warm-based in the ablation area where basal motion is required to account for the observed surface velocities, and generally cold-based in the accumulation area. Exceptions to this pattern occur in the lower accumulation area in the late summer, when localized areas of the glacier bed appear to reach the pressure-melting point due to the penetration of surface meltwater to the glacier bed via moulins. The inference that basal motion occurs throughout the winter in the lower ablation area is consistent with independent evidence from radio-echo sounding and meltwater chemistry for subglacial water storage in this region.

The magnitude of basal motion beneath the lower ablation area seems to increase substantially during the summer melt season. The increase is especially marked in the area downstream from a group of crevasses and large moulins by which five large supraglacial streams drain into the glacier in summer. Together, these streams drain much of the upper ablation and accumulation areas of the glacier.
This clearly suggests that the rate of basal motion is strongly influenced by the delivery of surface meltwaters to the glacier bed, even though much of the overlying ice is at sub-freezing temperatures. Longitudinal stresses seem to be an important influence on the flow of the glacier. Neglecting the effect on the flow of possible longitudinal variations in ice temperature, a longitudinal coupling length of 4 times the local ice thickness provides the best fit between observed and predicted surface velocities.

\section{ACKNOWLEDGEMENTS}

Funding and field logistics were provided by the University of Alberta Izaak Walton Killam Memorial Scholarship, the Natural Sciences and Engineering Research Council of Canada, the U.K. Natural Environment Research Council ARCICE programme, the Polar Continental Shelf Project (contribution No. 00901), the Geological Society of America, and the Canadian Circumpolar Institute of the University of Alberta. We thank the Nunavut Research Institute and the communities of Grise Fiord and Resolute Bay for permission to work at John Evans Glacier. W. Davis, D. Glowacki, A. Arendt, T. Wohlleben, J. Barker, C. Stuart, J. Davis, S. Boon and K. Heppenstall provided invaluable help in the field. We are grateful to T. Jóhannesson (Scientific Editor) and two anonymous referees for their useful comments.

\section{REFERENGES}

Andreasen, J.-O. 1985. Seasonal surface-velocity variations on a sub-polar glacier in West Greenland. f. Glaciol., 31 (109), 319-323.

Bingham, R. G., P.W. Nienow and M. J. Sharp. 2003. Intra-annual and intraseasonal flow dynamics of a High Arctic polythermal valley glacier. Ann. Glaciol., 37, 181-188.

Blatter, H. 1987. On the thermal regime of an Arctic valley glacier: a study of White Glacier, Axel Heiberg Island, N.W.T., Canada. f. Glaciol., $33(114), 200-211$.

Blatter, H. and G. Kappenberger. 1988. Mass balance and thermal regime of Laika ice cap, Coburg Island, N.W.T., Canada. F. Glaciol., 34(116), $102-110$

Copland, L. and M. Sharp. 2000. Radio-echo sounding determination of polythermal glacier hydrology. In Noon, D., G. F. Stickley and D. Longstaff, eds. GPR 2000, Eighth International Conference on Ground Penetrating Radar, 23-26 May 2000, Gold Coast, Australia. Bellingham, WA, International Society of Photo-optical Instrumentation Engineers, 59-64. (SPIE Proceedings 4084.)

Copland, L. and M. Sharp. 2001. Mapping thermal and hydrological conditions beneath a polythermal glacier with radio-echo sounding. F. Glaciol., 47(157), 232-242.

Copland, L., M. Sharp and P. Nienow. 2003. Links between short-term velocity variations and the subglacial hydrology of a predominantly cold polythermal glacier. f. Glaciol., 49 (166), 337-348.

Heppenstall, K.E. 2002. Chemical weathering in a glaciated carbonate catchment, Canadian High Arctic: implications for subglacial hydrology. (M.Sc. thesis, University of Alberta.)

Hodgkins, R. 1997. Glacier hydrology in Svalbard, Norwegian High Arctic. Quat. Sci. Rev., 16(9), 957-973.

Iken, A. 1974. Velocity fluctuations of an Arctic valley glacier; a study of the White Glacier, Axel Heiberg Island, Canadian Arctic Archipelago. Montréal, Que., McGill University. (Axel Heiberg Island Research Reports Glaciology 5.)

Iken, A. and R. A. Bindschadler. 1986. Combined measurements of subglacial water pressure and surface velocity of Findelengletscher, Switzerland: conclusions about drainage system and sliding mechanism. f. Glaciol., 32(110), 101-119.

Kamb, B. and K. A. Echelmeyer. 1986. Stress-gradient coupling in glacier flow: I. Longitudinal averaging of the influence of ice thickness and surface slope. 7. Glaciol., 32(111), 267-284.

Nye, J. F. 1952. The mechanics of glacier flow. f. Glaciol., 2(12), 82-93.

Nye, J. F. 1957. The distribution of stress and velocity in glaciers and icesheets. Proc. R. Soc. London, Ser. A, 239(1216), 113-133.

Nye, J. F. 1965. The flow of a glacier in a channel of rectangular, elliptic or parabolic cross-section. F. Glaciol., 5(41), 661-690.

Paterson, W. S. B. 1994. The physics of glaciers. Third edition. Oxford, etc., Elsevier. 
Rabus, B. T. and K. A. Echelmeyer. 1997. The flow of a polythermal glacier: McCall Glacier, Alaska, U.S.A. 7. Glaciol., 43(145), 522-536.

Skidmore, M. L. and M. J. Sharp. 1999. Drainage system behaviour of a High-Arctic polythermal glacier. Ann. Glaciol., 28, 209-215

Willis, I. C. 1995. Intra-annual variations in glacier motion: a review. Prog. Phys. Geogr., 19(1), 61-106.

Woodward, J., M. Sharp and A. Arendt. 1997. The influence of superimposed- ice formation on the sensitivity of glacier mass balance to climate change. Ann. Glaciol., 24, 186-190.

Zevenbergen, L.W. and C. R. Thorne. 1987. Quantitative analysis of land surface topography. Earth Surf. Processes Landforms, 12(1), 47-56.

Zwally, H. J., W. Abdalati, T. Herring, K. Larson, J. Saba and K. Steffen. 2002. Surface melt-induced acceleration of Greenland ice-sheet flow. Science, 297(5579), 218-222.

MS received 31 July 2001 and accepted in revised form 23 May 2003 